OPEN ACCESS

Edited by:

Jean El Cheikh,

American University of Beirut Medical

Center, Lebanon

Reviewed by:

Xiaoxia $\mathrm{Hu}$,

Ruijin Hospital, China

Marta Sonia González Pérez,

University Clinical Hospital of Santiago,

Spain

*Correspondence:

Yongxian $\mathrm{Hu}$

1313016@zju.edu.cn

He Huang

huanghe@zju.edu.cn

${ }^{t}$ These authors have contributed equally to this work

Specialty section:

This article was submitted to

Hematologic Malignancies,

a section of the journal

Frontiers in Oncology

Received: 02 August 2021

Accepted: 15 October 2021

Published: 01 November 2021

Citation:

Ding L, Wang $Y$, Hong $R$, Zhao $H$, Zhou L, Wei G, Wu W, Xu H, Zhang Y,

Luo Y, Shi J, Chang AH, Hu Y and Huang H (2021) Efficacy and Safety of Chimeric Antigen Receptor T Cells in Acute Lymphoblastic Leukemia With

Post-Transplant Relapse.

Front. Oncol. 11:750218.

doi: 10.3389/fonc.2021.750218

\section{Efficacy and Safety of Chimeric Antigen Receptor T Cells in Acute Lymphoblastic Leukemia With Post-Transplant Relapse}

\author{
Lijuan Ding $^{1,2,3,4 \dagger}$, Yiyun Wang ${ }^{1,2,3,4 \dagger}$, Ruimin Hong ${ }^{1,2,3,4}$, Houli Zhao ${ }^{1,2,3,4}$, \\ Linghui Zhou ${ }^{1,2,3,4}$, Guoqing Wei ${ }^{1,2,3,4}$, Wenjun $W^{1,2,3,4}$, Huijun $X u^{1,2,3,4}$, Yanlei Zhang ${ }^{5}$, \\ Yi Luo ${ }^{1,2,3,4}$, Jimin Shi ${ }^{1,2,3,4}$, Alex H. Chang ${ }^{5}$, Yongxian $\mathrm{Hu}^{1,2,3,4^{*}}$ and He Huang ${ }^{1,2,3,4^{*}}$ \\ ${ }^{1}$ Bone Marrow Transplantation Center, First Affiliated Hospital, College of Medicine, Zhejiang University, Hangzhou, China, \\ ${ }^{2}$ Liangzhu Laboratory, Zhejiang University Medical Center, Hangzhou, China, ${ }^{3}$ Institute of Hematology, Zhejiang University, \\ Hangzhou, China, ${ }^{4}$ Zhejiang Province Engineering Laboratory for Stem Cell and Immunity Therapy, Hangzhou, China, \\ 5 Shanghai YaKe Biotechnology Ltd, Shanghai, China
}

Twenty patients with relapsed B-ALL after HSCT were treated with CAR T cell therapy and were evaluated for efficacy and safety. Twelve patients previously received haploidentical transplantation, while 8 patients received HLA-matched transplantation. The median relapse time was 12 months (range, 4 to 72). Thirteen patients received autologous CAR T cells, and 7 patients received allogeneic CAR T cells, which were derived from transplant donors. The median infusion dose was $2.9 \times 106 / \mathrm{kg}$ (range, 0.33 to $12 \times 106 / \mathrm{kg}$ ). Nineteen patients were evaluated for efficacy, among which 17 patients (89.5\%) achieved MRD negative. The CR rates in the HLA-matched transplantation group and haploidentical transplantation group were 100\% (7/7) and 83.3\% (10/12), respectively. The median follow-up time was 9.80 months (range, 2.40 to 64.97$)$. Ten patients (50\%) died of relapse, 3 patients (15\%) died of infection, and 1 patient (5\%) died of aGVHD. Fifteen patients (75\%) developed CRS, including $3(20 \%)$ grade 1 CRS, $6(40 \%)$ grade 2 CRS, and 6 (40\%) grade 3 CRS. Ten patients (50\%) developed aGVHD, including $1(10 \%)$ grade I aGVHD, 6 (60\%) grade II aGVHD, and $3(30 \%)$ grade III aGVHD. The log rank test showed that CAR T cell origin was correlated with aGVHD occurrence in the haploidentical transplantation group $(P=0.005)$. The authors' study indicated that the initial efficacy and safety of CAR T cell therapy for patients with post-transplant relapse were satisfactory. However, aGVHD was a concern in patients with a history of haploidentical transplantation occupied with allogeneic CAR T cells, which warrants clinical attention.

Keywords: chimeric antigen receptor T cells, post-transplant relapse, acute graft versus host disease, cytokine release syndrome, acute lymphoblastic leukemia 


\section{INTRODUCTION}

The prognosis of relapsed acute lymphoblastic leukemia (ALL) after hematopoietic stem cell transplantation (HSCT) is dismal. A retrospective study of 465 cases of relapsed ALL after $1^{\text {st }}$ HSCT showed that the median survival time was only 5.5 months. The 1 -year, 2-year, and 5-year survival rates were $30 \pm 2 \%, 16 \pm 2 \%$ and $8 \pm 1 \%$, respectively (1). A study of 232 pediatric patients showed that the 3-year overall survival (OS) after relapse was $13 \%$ (2). For post-transplant relapses, donor lymphocyte infusion (DLI), second transplantation, intense chemotherapy and cytokine treatment have been tried as salvage regimens without significant clinical benefits. The success of DLI varies from 0 to $57.1 \%$ with mere increase in median survival by 6 months $(3,4)$. Noteworthy, treatment-related mortality after DLI is $5-20 \%$ and more than one-third of patients will develop acute and/or chronic GVHD after DLI (5). Second transplantation resulted in an OS of only $14 \%$ at 2 years among 245 patients (6). The poor performance and high expenditure of second transplantation have made it an unwise choice for posttransplant relapses. Failure of the above regimens highlights the need for novel alternative and more effective therapies.

In recent years, chimeric antigen receptor (CAR) $\mathrm{T}$ cell therapy has yielded pivotal success in hematological disease, especially in refractory/relapses (R/R) ALL. Autologous CD19 CAR T cells have shown significant antileukemia effects, with complete remission (CR) rates of 70 90\% (7-10). The cumulative incidence of relapse (CIR) and disease-free survival (DFS) brought by CAR T cell therapy itself are relatively short. Therefore, successful CAR $\mathrm{T}$ cell therapy are often followed by allo-HSCT. However, limited studies have focused on CAR T cells in the treatment of post-transplant relapses. For patients with a history of allo-HSCT, the source of CAR $T$ cells can be either the patient himself or the transplant donor, which is called allogeneic CAR T cells in this manuscript. Preclinical studies demonstrated that donor-derived CAR T cells were active in allogeneic recipients but had the capacity to induce lethal GVHD (11). Hu Y et al. previously reported a retrospective comparison of allogenic and autologous CD19 CAR T cell therapy in 31 ALL patients, including 14 patients with post-transplant relapses (12). Univariate subgroup analysis of allogenic CAR T group showed the presence of cGVHD at the time of $\mathrm{T}$ cell collection was significantly associated with less than 6-month relapses $(P=0.022)$. aGVHD occurred in 3 patients with posttransplant relapses.

However, the long-term efficacy and safety of CAR T cells in the treatment of post-transplant relapses have not yet been systematically clarified. Here we report the retrospective clinical results of CAR T cell therapy in 20 patients with relapsed ALL after HLA-matched or haploidentical transplantation from our hospital.

\section{METHODS}

\section{Patients and Study Design}

Twenty patients with relapsed ALL after HLA-matched or haploidentical transplantation were enrolled in this retrospective study (Figure 1B) and were administered CAR-T cell therapy at the
First Affiliated Hospital of Zhejiang University from August 2015 to September 2020. All these patients had received at least one transplantation and remained CR for a period of time afterwards. However, there were no effective regimens when they relapsed after transplantation. None of the patients had been treated with cellimmunotherapy, except one patient who received the first CAR T cell therapy before allo-HSCT. The clinical data were extracted from the electronic medical record system of patients enrolled in the trial ChiCTR-ORN-16008948 and ChiCTR1900023957. The study was approved by the Ethics Committee of the First Affiliated Hospital of Zhejiang University School of Medicine and was conducted in accordance with internationally recognized good clinical practice guidelines.

\section{CAR T Cell Generation}

The protocol of CAR-T cell generation in our center was described previously (12). Briefly, $\mathrm{CD}^{+} \mathrm{T}$ cells were separated from peripheral blood mononuclear cells and then transduced with a lentiviral vector containing a CAR with a CD3-zeta domain and 4-1BB domain. CAR T cells were expanded for another 5 days until the numbers were sufficient for infusion (Figure 1A).

\section{Treatment and Detection}

All patients received conditioning chemotherapy with concurrent cyclophosphamide $\left(500-750 \mathrm{mg} / \mathrm{m}^{2}\right)$ and fludarabine $\left(30-50 \mathrm{mg} / \mathrm{m}^{2}\right)$ administration for 3 days followed by CAR T cell infusion. CRS and aGVHD prevention were not performed. The classification of CRS and aGVHD refer to the standard $(13,14)$. Bone marrow was evaluated in 1 month after the initial infusion by standard pathological testing. Then patients were followed-up in the clinic every three months.

\section{Statistical Analysis}

Measurement data were described using means with standard deviations or medians with ranges. Enumeration data are presented as frequencies (\%). Kaplan-Meier (KM) curves for PFS were generated, and the log-rank test was used to compare differences between subgroups. The median follow-up time was estimated using reverse Kaplan-Meier curves. All $P$ values represented were two-sided, and results were considered statistically significant when $P<0.05\left(^{*}\right)$. Data were analyzed using IBM SPSS Statistics 24. Prism (version 7.0) was used to generate the graphs.

\section{RESULTS}

\section{Patient Characteristics}

The 20 patients were evaluated for efficacy and safety. The characteristics of the patients are shown in Table 1. Ten patients were male. Median age was 27 years old (range, 15 to 66). The proportion of $\mathrm{Ph}+\mathrm{ALL}$ was $15 \%$ (3/20). Twelve patients previously received haploidentical transplantation, and 8 patients received HLA-matched transplantation. The median 

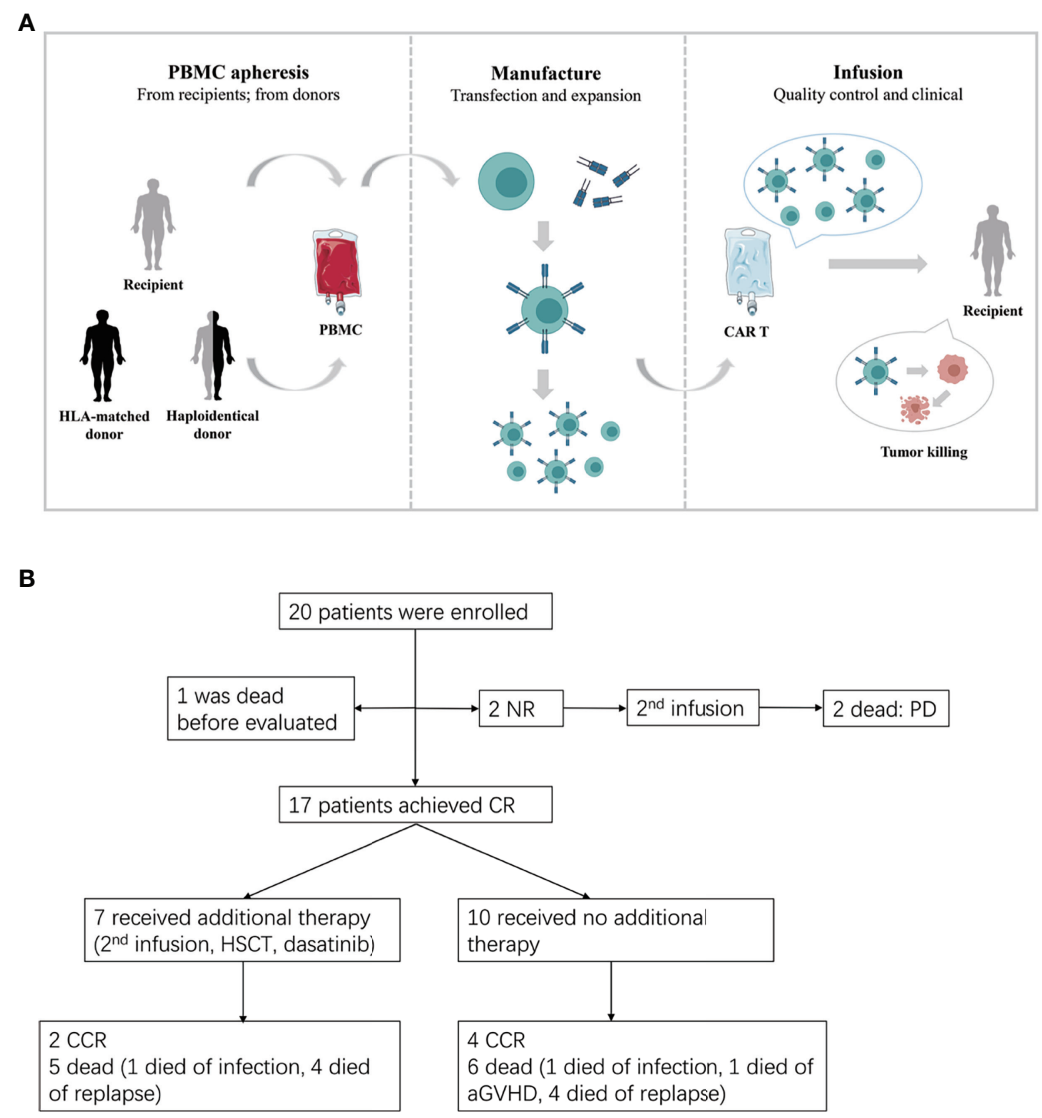

FIGURE 1 | (A) The procedure of autologous or allogeneic CAR T cells in patients with post-transplant relapse. Peripheral blood mononuclear cells (PBMC) are apheresised from recipients or transplantation donors (including HLA-matched donor and haploidentical donor). CD3 positive T cells are selected and stimulated by CD3/CD28 dynabeads. Then T cells were transfected by lentivirus to generate CAR T cells. Lastly, the qualified CAR T cells are infused to recipients after expansion. (B) Study flow, enrollment, treatment and follow-up of patients. CR, complete remission; CCR, continued CR; NR, non-remission; PD, progressive disease.

relapse time after transplantation was 12 months (range, 4 to 72 ). Further, 13 patients received autologous CAR T cells, and 7 patients received allogeneic CAR T cells. Allogeneic CAR-T cells were manufactured from transplant donors, which were adopted for cases where there were insufficient or deficient autologous $\mathrm{T}$ lymphocytes. The median infusion dose was $2.89 \times 10^{6} / \mathrm{kg}$ (range, 0.33 to $12 \times 10^{6} / \mathrm{kg}$ ). All the patients were enrolled in the CAR-T treatment trial only after they had stopped chemotherapy for more than 1 month. There were no statistically significant differences in sex, age, disease karyotype, or leukemia burden.

\section{Efficacy}

Nineteen of the 20 patients survived for more than one month were evaluated for efficacy, except one patient who died of severe lung infection within one week. Among the19 patients, 17 patients achieved MRD negative in one month confirmed by bone marrow examination. The complete remission (CR) rate was $89.5 \%$. The CR rates in the HLA-matched transplantation group and haploidentical transplantation group were $100 \%$ (7/ 7) and $83.3 \%(10 / 12)$, respectively. Considering CAR T cell origin, The CR rates of allogeneic CAR T cells and autologous
CAR T cells were $85.7 \%(6 / 7)$ and $91.7 \%$ (11/12), respectively. More specifically, the CR rates of allogeneic CAR T cells and autologous CAR T cells in the HLA-matched transplantation group and haploidentical transplantation group were 100\% (3/ 3), $100 \%(4 / 4), 87.5 \%(7 / 8)$ and $75 \%(3 / 4)$. Due to the lack of close monitoring in the preliminary clinical trials, the CAR-T cell expansion in vivo were not detected continuously, which made it impossible to learn the CAR $\mathrm{T}$ cell dynamics in different groups.

Treatment and the response duration of each patient was shown in Figure 2. The median follow-up time was 9.80 months (range, 2.40 to 64.97). The median follow-up time in the HLA-matched transplantation group and haploidentical transplantation group were 8.57 months (range, 6.07 to 37.67 ) and 11.90 months (range, 2.40 to 64.97). There were 10 patients died of relapse or progressive disease, 3 patients died of infection, and 1 patient died of aGVHD. Six patients survived before this manuscript. Patient 7 with extramedullary relapse received two more CAR T cell therapies and used dasatinib as a maintenance therapy (15). Patients 13, 15, 18, 19 and 20 maintained CR by CAR $\mathrm{T}$ cell therapy and chemotherapy. 
TABLE 1 | Patients baseline and therapy-related characteristics.

\begin{tabular}{|c|c|}
\hline \multicolumn{2}{|l|}{ Gender, no. (\%) } \\
\hline Female & $10(50)$ \\
\hline Male & $10(50)$ \\
\hline Age, range (year) & $27(15-66)$ \\
\hline Hyperploidy, n (\%) & $1(5)$ \\
\hline Hypoplodiy, n (\%) & $0(0)$ \\
\hline Complex karyotype, n (\%) & $2(10)$ \\
\hline BCR-ABL1, n (\%) & $5(25)$ \\
\hline ETV6-RUNX1, n (\%) & $0(0)$ \\
\hline E2A-PBX1, n (\%) & $0(0)$ \\
\hline KMT2A rearranged, $\mathrm{n}(\%)$ & $1(5)$ \\
\hline IKZF1 mutation, n (\%) & $0(0)$ \\
\hline Poor-risk cytogenetics, n (\%) & $4(20)$ \\
\hline Good-risk cytogenetics, n (\%) & $1(5)$ \\
\hline Leukemia burden, range (\%) & $11.96(0-83)$ \\
\hline Prior numbers of therapy, range(no.) & $4(1-9)$ \\
\hline Numbers of relapses, range (no.) & $1(1-3)$ \\
\hline \multicolumn{2}{|l|}{ Transplantation type, no. (\%) } \\
\hline Matched transplantation & $8(40)$ \\
\hline Haploidentical transplantation & $12(60)$ \\
\hline Relapse time after transplantation, range (month) & $12(4-72)$ \\
\hline CAR T-cell dose, range $\left(\times 10^{6} / \mathrm{kg}\right)$ & $2.89(0.33-12)$ \\
\hline \multicolumn{2}{|l|}{ CAR T origin, no. (\%) } \\
\hline Autologous & $13(65)$ \\
\hline Donor & $7(35)$ \\
\hline
\end{tabular}

\section{Toxicitiy CRS}

Fifteen patients (75\%) developed different degrees of CRS, including 3 cases (20\%) of grade 1 CRS, 6 cases $(40 \%)$ of grade 2 CRS, and 6 cases (40\%) of grade 3 CRS. No grade 4 and grade 5 CRS occurred. The incidence rates of different grades of CRS were shown in Figure 3. One patient had neurological symptoms of epilepsy, elevated cerebrospinal fluid cytokines, and severe CRS. CRS and neurological symptoms in 15 patients lasted for a short time and were quickly controlled after hormone therapy. No patients died directly of CRS or neurotoxicity.

\section{aGVHD}

Allogeneic CAR T cells brings the concern of aGVHD. In our study, $10(50 \%)$ patients developed the symptoms of aGVHD, including 1 (10\%) grade I aGVHD, $6(60 \%)$ grade II aGVHD, and $3(30 \%)$ grade III aGVHD. Among them, the aGVHD incidence rates in the HLA-matched transplantation group and the haploidentical transplantation group were $50 \%(4 / 8)$ and $50 \%$ (6/12), respectively ( $P=0.725$, Table 2$)$. Benefiting from our clinical experience in the treatment of aGVHD after alloHSCT, the symptoms were effectively controlled by

A
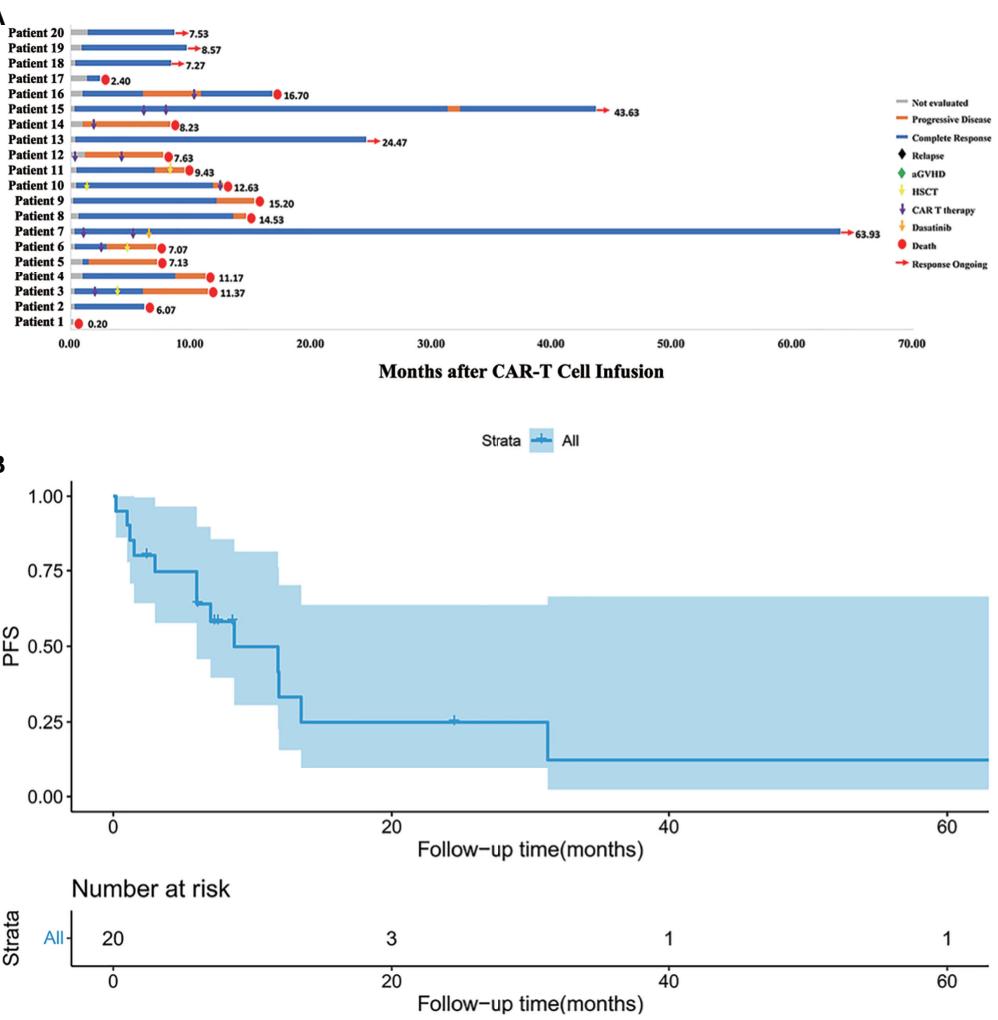

FIGURE 2 | (A) Follow-up results of each patient. Patient 1 died of severe lung infection within one week after CAR T cell infusion. Patients 12 and 14 progressed even after second CAR T cell infusion. Patient 7 with extramedullary relapse maintained CR with dasatinib therapy. Patients 13, 15, 18, 19, 20 maintained CR for now by CAR T cell therapy and chemotherapy. Other patients eventually died of relapse or severe complication. (B) Kaplan-Meier (KM) curves for PFS. The median PFS time was 8.7 months, and the 1 -year PFS was $33.2 \%$. 

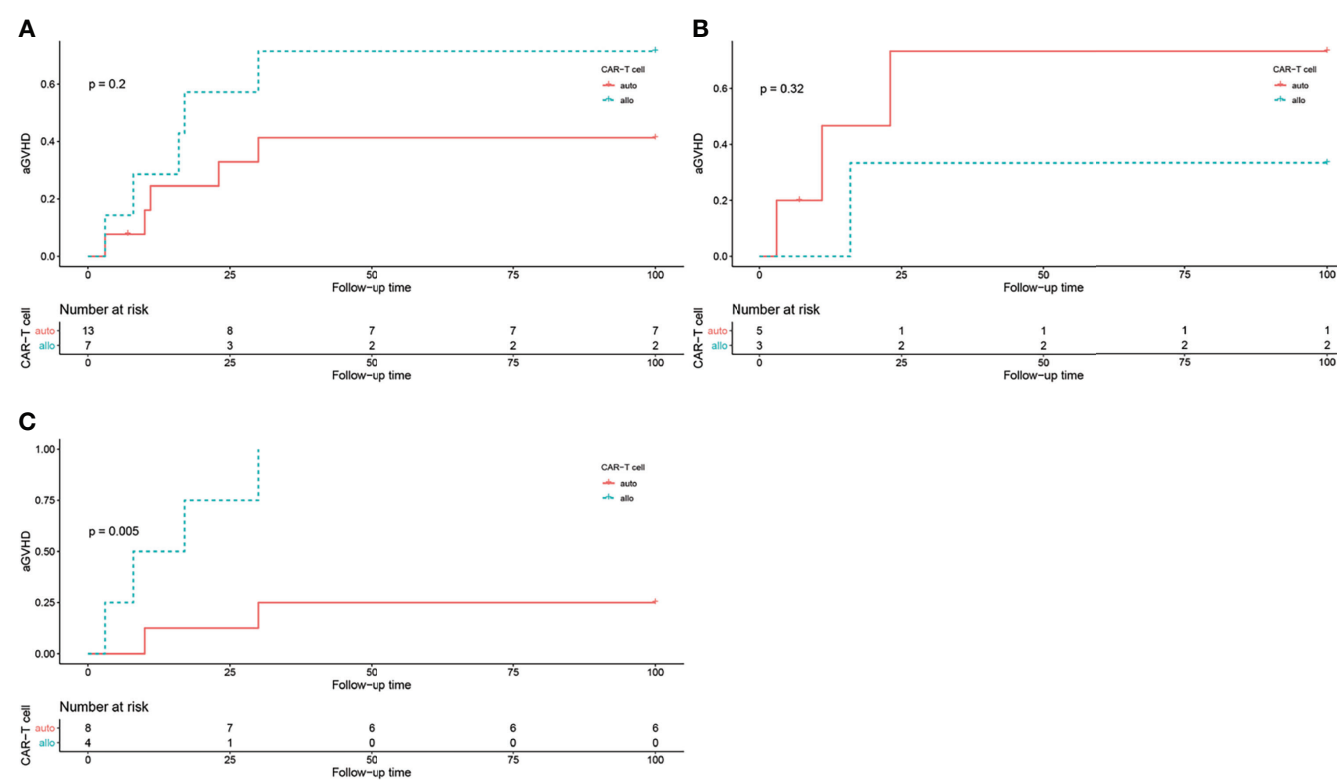

FIGURE 3 | The log rank test of aGVHD incidence in different groups, grouped by CAR T cell origin. (A) aGVHD incidence in all patients, P = 0.2. (B) aGVHD incidence in all patients in HLA-matched transplantation group, $P=0.32$. (C) aGVHD incidence in all patients in haploidentical transplantation group, $\mathrm{P}=0.005$.

TABLE 2 | Univariate analysis of possible factors related to aGVHD.

\begin{tabular}{|c|c|c|c|}
\hline Factors & $\begin{array}{l}\text { No. of patients } \\
\text { (\%) }\end{array}$ & $\begin{array}{c}\text { No. of aGVHD } \\
(\%)\end{array}$ & $\begin{array}{c}P \\
\text { value }\end{array}$ \\
\hline Overall & $20(100)$ & $10(50)$ & \\
\hline Gender & & & 0.464 \\
\hline Male & $10(50)$ & $6(60)$ & \\
\hline Female & $10(50)$ & $4(40)$ & \\
\hline CAR T cell source & & & 0.22 \\
\hline Autologous & $13(65)$ & $5(38.5)$ & \\
\hline Allogeneic & $7(35)$ & $5(71.4)$ & \\
\hline History of DLI & & & 0.25 \\
\hline Yes & $6(30)$ & $5(83.3)$ & \\
\hline No & $14(70)$ & $5(35.7)$ & \\
\hline Transplantation type & & & 0.725 \\
\hline Matched transplantation & $8(40)$ & $4(50)$ & \\
\hline Haploidentical transplantation & $12(60)$ & $6(50)$ & \\
\hline aGVHD post-HSCT & & & 0.534 \\
\hline Yes & $8(40)$ & $3(37.5)$ & \\
\hline No & $12(60)$ & $7(58.3)$ & \\
\hline $\begin{array}{l}\text { Duration of CR post-HSCT } \\
\text { (months) }\end{array}$ & & & 0.198 \\
\hline $0-6$ & $6(30)$ & $5(83.3)$ & \\
\hline $7-12$ & $5(25)$ & $1(20)$ & \\
\hline$>12$ & $9(45)$ & $4(44.4)$ & \\
\hline CRS grade & & & 0.487 \\
\hline $0-2$ & $14(70)$ & $7(50)$ & \\
\hline 3 & $6(30)$ & $3(50)$ & \\
\hline Agranulocytosis time (days) & & & 0.373 \\
\hline $0-14$ & $15(75)$ & $8(53.3)$ & \\
\hline $15-28$ & $4(20)$ & $2(50)$ & \\
\hline$>28$ & $1(5)$ & $0(0)$ & \\
\hline Chromosome & & & 0.659 \\
\hline $\mathrm{Ph}+$ & $3(15)$ & $1(33.3)$ & \\
\hline $\mathrm{Ph}-$ & $17(85)$ & $9(62.9)$ & \\
\hline
\end{tabular}

immunosuppressants, which include etanercept, cyclosporine, tacrolimus and methylprednisolone.

In the HLA-matched transplantation group, 3 out of 5 patients (60\%) received autologous CAR T cells and 1 out of 3 patients (33.3\%) received allogeneic CAR T cells developed aGVHD. While in the haploidentical transplantation group, 2 out of 8 patients received autologous CAR T cells and all 4 patients received allogeneic CAR T cells developed aGVHD. The log-rank test showed that CAR T cell origin was correlated with aGVHD occurrence in the haploidentical transplantation group $(P=0.005$, Figure 3).

\section{DISCUSSION}

Relapse after allo-HSCT has always been a considerable obstacle in the treatment of $\mathrm{R} / \mathrm{R}$ ALL. The remission rate of second transplantation and DLI treatment are relatively unsatisfactory (3-6). Therefore, new treatment methods are urgently needed in patients with post-transplant relapse. CAR $\mathrm{T}$ cell therapy, which has emerged as a promising treatment for hematological malignancies in recent years, has achieved high initial response rates and long-term remission in R/R ALL. However, research of CAR T cells in the treatment of post-transplant relapse is still in its infancy. Brudno et al. used donor-derived CD19 CAR T cells in patients with persistent B-cell malignancies after allo-HSCT. Eight out of 20 patients showed tumor regression without aGVHD flare, including six achieving complete remission (CR) and two achieving partial remission (PR) (16). Maude et al. performed CD19 CAR T cell therapy on 18 patients who relapsed after alloHSCT. There was no significant difference in terms of event-free survival (EFS) or overall survival (OS) between patients who had 
received allo-HSCT and those who had not $(\mathrm{P}=0.21$ for $\mathrm{EFS}, \mathrm{P}=$ 0.24 for OS) (17). The authors' study showed a CR rate of $89.5 \%$ (17/19). The CR rates of the HLA-matched transplantation group and haploidentical transplantation group were 100\% (7/7) and 83.3\% (10/12), respectively.

Relapse after CAR $\mathrm{T}$ cell therapy remains a big obstacle that influence patients' efficacy and long-term survival. Most patients relapse within 1 year after CART treatment (18). In the authors' study, the median relapse time was 6.07 months (range, 1.50 to 31.27). At present, the mechanism of relapse after CAR-T cell therapy is still unclear. According to current studies, CD19-negative relapse is related to the loss of CD19 gene (19) or myeloid transformation (20). The possible mechanism of CD19-positive relapse includes CAR-T cell exhaustion and abnormal CAR-T cell function caused by immunosuppressive cells and factors in the bone marrow microenvironment (such as mesenchymal stem cells (MSCs), regulatory $\mathrm{T}$ cells (Treg), bone marrow-derived suppressive cells (MDSC), TGF- $\beta$, etc.) (21).

Toxicities after CAR T cell infusion include CRS, tumor lysis syndrome (TLS), immune effector cell-associated neurotoxicity syndrome (ICANS) and B-cell aplasia. aGVHD was brought to concern when allogeneic CAR T cells were applied. aGVHD occurs when the Tlymphocytes in allogeneic donor transplants attack the recipient's target cells, which is stimulated by a series of "cytokine storms" initiated by the recipient. Studies have confirmed that CAR $\mathrm{T}$ cells can relieve patients with post-transplant relapse without a flare of aGVHD. For recipient-derived CAR-T cell therapy, Park et al. (18) and Lee et al. (9) reported a total of 25 patients with no GVHD observed. For donor-derived CAR T cell therapy, Cruz et al. (22) and Kochenderfer et al. (23) reported a total of 38 patients without aGVHD flare.

From the above data, either recipient-derived or donor-derived CAR $\mathrm{T}$ cell therapy has good efficacy in the treatment of posttransplant relapse, with low risk of aGVHD. However, the reported data are focused on relapse after HLA-matched transplantation. Limited data of CAR T cells in relapse after haploidentical transplantation from China showed different results. Huang XJ et al. reported that out of 34 evaluable patients, 7 patients developed GVHD, with mild chronic GVHD in 1 case and aGVHD in 6 cases (2 grade II aGVHD, 3 grade III aGVHD and 1 grade IV aGVHD). The occurrence of GVHD had a poor effect on survival (24). A study by Zhang $\mathrm{X}$ et al. showed that 2 out of 43 patients with posttransplant relapse developed $\leq$ grade II aGVHD when receiving allogeneic CD19 CAR T cells (25). In another study focusing on CAR T cell therapy in post-transplant patients, the development of aGVHD was observed in 10 patients $(66.67 \%)$, with 6 patients developed grade I-II of aGVHD, while 4 patients developed grade III-IV of aGVHD (26). In the authors' report, out of 20 patients, 10 (50\%) developed new-onset aGVHD after CAR T cell infusion. The log rank test showed that high aGVHD occurrence was related to the source of CAR T cells in the haploidentical transplantation group $(P=0.005)$.

According to the above studies, patients were likely to develop aGVHD 3 to 4 weeks after CAR T cell treatment. This may be related to the survival time of CAR T cells. aGVHD usually occurs in 1 month after lymphocyte infusion, equal to the survival time of CAR $\mathrm{T}$ cells in vivo (27). Therefore, the possibility of aGVHD is low. The occurrence of aGVHD is related to the dose of infused lymphocytes. The number of CAR $\mathrm{T}$ cells infused was between $10 \mathrm{e}^{6}$ and $10 \mathrm{e}^{7}$, which was less than the threshold of $10 \mathrm{e}^{7}$ for aGVHD (28). On the other hand, fludarabine and cyclosporine as GVHD prophylaxis in bone marrow transplants, may reduce the risk of CAR T-related aGVHD (29). Different CAR structures and different stimulation intensities also cause differences in aGVHD occurrence. Kawalekar et al. believed that CAR T cells with $4-1 \mathrm{BB}$ as a costimulatory molecule were less activated and did not often cause aGVHD (30). Tao Wang et al. used CAR T cells as DLI treatment, which significantly prolonged the survival period. They found a lower incidence of aGVHD than that of traditional DLI (31).

In essence, both aGVHD and CRS are inflammatory cascades. Nevertheless, aGVHD and CRS share similar symptoms in mild cases. Therefore, sometimes it's difficult to distinguish between the two common complications. Clinically, CRS usually occurs within 1-14 days after CAR T cell infusion (32), while aGVHD can happen in 100 days after transplantation (13). CAR T-related CRS is believed to be caused by the activation of myeloid cells by highly activated T cells, and IL-6 released from myeloid cells has been shown to be an important contributor (33). Pre-use of IL-6 and IL-1 receptor antagonists can prevent CRS without compromising tumor remission, but only IL-1 receptor blockade can prevent neurotoxicity. IL- 2 secreted by Th1 cells is the most important cytokine that initiates aGVHD (34). Animal experiments have found that in the first two days of aGVHD, the IL-2 produced by donor CD4+ T cells reaches the highest level. Mice injected with IL-2 can aggravate the degree of aGVHD (35). Another major cytokine is IFN- $\gamma$, with the peak level appears on the 7th day after transplantation (36). Therefore, cytokine detection can also distinguish aGVHD and CRS.

\section{CONCLUSION}

In summary, the initial efficacy and safety of CAR T cell therapy for patients with relapsed B-ALL after HSCT were satisfactory. Relapse after CAR T cell therapy remains a big obstacle that influents patients' long-term survival. The incidence of aGVHD was higher in patients with a previous history of haploidentical transplantation, making it a concern for CAR T cell therapy, especially for patients receiving allogeneic CAR $\mathrm{T}$ cells. The treatment of aGVHD after CAR T cell therapy is the same as the treatment of aGVHD after HSCT. We are conducting further research with a larger sample size so that more credible conclusions can be drawn.

\section{DATA AVAILABILITY STATEMENT}

The original contributions presented in the study are included in the article/supplementary material. Further inquiries can be directed to the corresponding author. 


\section{ETHICS STATEMENT}

The studies involving human participants were reviewed and approved by the Ethics Committee of the First Affiliated Hospital of Zhejiang University School of Medicine. Written informed consent to participate in this study was provided by the participants' legal guardian/next of kin.

\section{AUTHOR CONTRIBUTIONS}

LD and YW contributed equally to the work. They collected patients' data and wrote the manuscript together. $\mathrm{RH}, \mathrm{HZ}$, and LZ participated in the data collection and analysis. GW, WW, $\mathrm{YL}$, and JS, as clinicians, participated in the patient's diagnosis and treatment process, and provided valuable clinical data. HX, $\mathrm{YZ}$, and $\mathrm{AC}$ were responsible for the preparation and quality inspection of CAR T cells. $\mathrm{HH}$ and $\mathrm{YH}$ as corresponding authors,

\section{REFERENCES}

1. Spyridonidis A, Labopin M, Schmid C, Volin L, Yakoub-Agha I, Stadler M, et al. Outcomes and Prognostic Factors of Adults With Acute Lymphoblastic Leukemia Who Relapse After Allogeneic Hematopoietic Cell Transplantation. An Analysis on Behalf of the Acute Leukemia Working Party of EBMT. Leukemia (2012) 26(6):1211-7. doi: 10.1038/leu.2011.351

2. Dahlberg A, Leisenring W, Bleakley M, Meshinchi S, Baker KS, Summers C, et al. Prognosis of Relapse After Hematopoietic Cell Transplant (HCT) for Treatment of Leukemia or Myelodysplastic Syndrome (MDS) in Children. Bone Marrow Transplant (2019) 54(8):1337-45. doi: 10.1038/s41409-019-0438-Z

3. Collins RH, Shpilberg O, Drobyski WR, Porter DL, Giralt S, Champlin N, et al. Donor Leukocyte Infusions in 140 Patients With Relapsed Malignancy After Allogeneic Bone Marrow Transplantation. J Clin Oncol (1997) 15 (2):433-44. doi: 10.1200/JCO.1997.15.2.433

4. Levine JE, Barrett AJ, Zhang MJ, Arora M, Pulsipher MA, Bunin N, et al. Donor Leukocyte Infusions to Treat Hematologic Malignancy Relapse Following Allo-SCT in a Pediatric Population. Bone Marrow Transplant (2008) 42(3):201-5. doi: 10.1038/bmt.2008.135

5. Tomblyn M, Lazarus HM. Donor Lymphocyte Infusions: The Long and Winding Road: How Should it be Traveled? Bone Marrow Transplant (2008) 42(9):569-79. doi: 10.1038/bmt.2008.259

6. Kolb HJ. Graft-Versus-Leukemia Effects of Transplantation and Donor Lymphocytes. Blood (2008) 112(12):4371-83. doi: 10.1182/blood-2008-03077974

7. Dong LJ, Chang LJ, Gao ZY, Lu DP, Zhang JP, Wang JB, et al. Chimeric Antigen Receptor 4scar19-Modified T Cells in Acute Lymphoid Leukemia: A Phase II Multi-Center Clinical Trial in China. Blood (2015) 126(23):3774. doi: 10.1182/blood.V126.23.3774.3774

8. Grupp SA, Maude SL, Shaw PA, Aplenc R, Barrett DM, Callahan C, et al. Durable Remissions in Children With Relapsed/Refractory ALL Treated With T Cells Engineered With a CD19-Targeted Chimeric Antigen Receptor (Ct1019). Blood (2015) 126(23):681. doi: 10.1182/blood.V126. 23.681.681

9. Lee DW, Kochenderfer JN, Stetler-Stevenson M, Cui YZK, Delbrook C, Feldman SA, et al. T Cells Expressing CD19 Chimeric Antigen Receptors for Acute Lymphoblastic Leukaemia in Children and Young Adults: A Phase 1 Dose-Escalation Trial. Lancet (2015) 385(9967):517-28. doi: 10.1016/ S0140-6736(14)61403-3

10. Turtle CJ, Hanafi LA, Berger C, Gooley TA, Cherian S, Hudecek M, et al. CD19 CAR-T Cells of Defined CD4(+): CD8(+) Composition in Adult B Cell ALL Patients. J Clin Invest (2016) 126(6):2123-38. doi: 10.1172/JCI85309

11. Jacoby E, Yang YM, Qin HY, Chien CD, Kochenderfer JN, Fry TJ, et al. Murine Allogeneic CD19 CAR T Cells Harbor Potent Antileukemic Activity guided the entire research and manuscript writing. All authors contributed to the article and approved the submitted version.

\section{FUNDING}

This work was supported by grants from the National Natural Science Foundation of China (81730008, 81970137), the Key Project of Science and Technology Department of Zhejiang Province (2018C03016-2, 2020C03G2013586), and the Key Research and Development Program of Zhejiang Province (2019C03016).

\section{ACKNOWLEDGMENTS}

We would like to thank the patients for participating in this study and the help of medical and nurse team on patients' care.

But Have the Potential to Mediate Lethal GVHD. Blood (2016) 127(10):136170. doi: 10.1182/blood-2015-08-664250

12. Hu YX, Wang JS, Wei CQ, Yu J, Luo Y, Shi JM, et al. A Retrospective Comparison of Allogenic and Autologous Chimeric Antigen Receptor T Cell Therapy Targeting CD19 in Patients With Relapsed/Refractory Acute Lymphoblastic Leukemia. Bone Marrow Transplant (2019) 54(8):1208-17. doi: 10.1038/s41409-018-0403-2

13. Aladag E, Kelkitli E, Goker H. Acute Graft-Versus-Host Disease: A Brief Review. Turkish J Hematol (2020) 37(1):1-4.

14. Lee DW, Gardner R, Porter DL, Louis CU, Ahmed N, Jensen M, et al. Current Concepts in the Diagnosis and Management of Cytokine Release Syndrome. Blood (2014) 124(2):188-95. doi: 10.1182/blood-2014-05-552729

15. Yu J, Hu Y, Pu C, Liang Z, Cui Q, Zhang H, et al. Successful Chimeric Ag Receptor Modified T Cell Therapy for Isolated Testicular Relapse After Hematopoietic Cell Transplantation in an Acute Lymphoblastic Leukemia Patient. Bone Marrow Transplant (2017) 52(7):1065-7. doi: 10.1038/ bmt.2017.64

16. Brudno JN, Somerville RPT, Shi V, Rose JJ, Halverson DC, Fowler DH, et al. Allogeneic T Cells That Express an Anti-CD19 Chimeric Antigen Receptor Induce Remissions of B-Cell Malignancies That Progress After Allogeneic Hematopoietic Stem-Cell Transplantation Without Causing Graft-VersusHost Disease. J Clin Oncol (2016) 34(10):1112-+. doi: 10.1200/ JCO.2015.64.5929

17. Maude SL, Frey N, Shaw PA, Aplenc R, Barrett DM, Bunin NJ, et al. Chimeric Antigen Receptor T Cells for Sustained Remissions in Leukemia. N Engl J Med (2014) 371(16):1507-17. doi: 10.1056/NEJMoa1407222

18. Park JH, Riviere I, Gonen M, Wang XY, Senechal B, Curran KJ, et al. LongTerm Follow-Up of CD19 CAR Therapy in Acute Lymphoblastic Leukemia. New Engl J Med (2018) 378(5):449-59. doi: 10.1056/NEJMoa1709919

19. Sotillo E, Barrett DM, Black KL, Bagashev A, Oldridge D, Wu G, et al. Convergence of Acquired Mutations and Alternative Splicing of CD19 Enables Resistance to CART-19 Immunotherapy. Cancer Discov (2015) 5 (12):1282-95. doi: 10.1158/2159-8290.CD-15-1020

20. Jacoby E, Nguyen SM, Fountaine TJ, Welp K, Gryder B, Qin H, et al. CD19 CAR Immune Pressure Induces B-Precursor Acute Lymphoblastic Leukaemia Lineage Switch Exposing Inherent Leukaemic Plasticity. Nat Commun (2016) 7:12320. doi: $10.1038 /$ ncomms 12320

21. Wang J, Hu Y, Huang H. Acute Lymphoblastic Leukemia Relapse After CD19-Targeted Chimeric Antigen Receptor T Cell Therapy. J Leukoc Biol (2017) 102(6):1347-56. doi: 10.1189/jlb.5RU0817-315R

22. Cruz CR, Micklethwaite KP, Savoldo B, Ramos CA, Lam S, Ku S, et al. Infusion of Donor-Derived CD19-Redirected Virus-Specific T Cells for B-Cell Malignancies Relapsed After Allogeneic Stem Cell Transplant: A Phase 1 Study. Blood (2013) 122(17):2965-73. doi: 10.1182/blood-2013-06-506741 
23. Kochenderfer JN, Dudley ME, Carpenter RO, Kassim SH, Rose JJ, Telford WG, et al. Donor-Derived CD19-Targeted T Cells Cause Regression of Malignancy Persisting After Allogeneic Hematopoietic Stem Cell Transplantation. Blood (2013) 122(25):4129-39. doi: 10.1182/blood-2013-08-519413

24. Chen YH, Zhang X, Cheng YF, Chen H, Mo XD, Yan CH, et al. Long-Term Follow-Up of CD19 Chimeric Antigen Receptor T-Cell Therapy for Relapsed/ Refractory Acute Lymphoblastic Leukemia After Allogeneic Hematopoietic Stem Cell Transplantation. Cytotherapy (2020) 22(12):755-61. doi: 10.1016/ j.jcyt.2020.08.002

25. Zhang C, Wang XQ, Zhang RL, Liu F, Wang Y, Yan ZL, et al. Donor-Derived CD19 CAR-T Cell Therapy of Relapse of CD19-Positive B-ALL Post Allotransplant. Leukemia (2020) 35(6):1563-70. doi: 10.1038/s41375-02001056-6

26. Liu PJ, Liu MJ, Lyu CC, Lu WY, Cui R, Wang J, et al. Acute Graft-Versus-Host Disease After Humanized Anti-CD19-CAR T Therapy in Relapsed B-ALL Patients After Allogeneic Hematopoietic Stem Cell Transplant. Front Oncol (2020) 10:573822. doi: 10.3389/fonc.2020.573822

27. Frey NV, Porter DL. Graft-Versus-Host Disease After Donor Leukocyte Infusions: Presentation and Management. Best Pract Res Clin Haematol (2008) 21(2):205-22. doi: 10.1016/j.beha.2008.02.007

28. Ghosh A, Smith M, James SE, Davila ML, Velardi E, Argyropoulos K, et al. Donor CD19 CAR T Cells Exert Potent Graft-Versus-Lymphoma Activity With Diminished Graft-Versus-Host Activity. Nat Med (2017) 23(2):242-9. doi: $10.1038 / \mathrm{nm} .4258$

29. Gorfinkel L, Demsky C, Pashankar F, Kupfer G, Shah NC. Bone Marrow Transplant Using Fludarabine-Based Reduced Intensity Conditioning Regimen With In Vivo T Cell Depletion in Patients With Fanconi Anemia. Pediatr Transplant (2021) 25(4):e14009. doi: 10.1111/petr.14009

30. Kawalekar OU, O'Connor RS, Fraietta JA, Guo L, McGettigan SE, Posey AD, et al. Distinct Signaling of Coreceptors Regulates Specific Metabolism Pathways and Impacts Memory Development in CAR T Cells. Immunity (2016) 44(2):380-90. doi: 10.1016/j.immuni.2016.01.021

31. Wang T, Gao L, Hu X, Liu B, Chen J, Zhang W, et al. Chimeric Antigen Receptor-Modified Donor Lymphocyte Infusion Improves the Survival of Acute Lymphoblastic Leukemia Patients With Relapsed Diseases After Allogeneic Hematopoietic Stem Cell Transplantation. J Immunother (2019) 42(3):81-8. doi: 10.1097/CJI.0000000000000257
32. Frey N, Porter D. Cytokine Release Syndrome With Chimeric Antigen Receptor T Cell Therapy. Biol Blood Marrow Transplant (2019) 25(4):e1237. doi: 10.1016/j.bbmt.2018.12.756

33. Norelli M, Camisa B, Barbiera G, Falcone L, Purevdorj A, Genua M, et al. Monocyte-Derived IL-1 and IL-6 are Differentially Required for CytokineRelease Syndrome and Neurotoxicity Due to CAR T Cells. Nat Med (2018) 24 (6):739-48. doi: 10.1038/s41591-018-0036-4

34. Ferrara JL, Cooke KR, Pan L, Krenger W. The Immunopathophysiology of Acute Graft-Versus-Host-Disease. Stem Cells (1996) 14(5):473-89. doi: 10.1002/stem. 140473

35. Fowler DH, Gress RE. Th2 and Tc2 Cells in the Regulation of GVHD, GVL, and Graft Rejection: Considerations for the Allogeneic Transplantation Therapy of Leukemia and Lymphoma. Leuk Lymphoma (2000) 38(34):221-34. doi: 10.3109/10428190009087014

36. Yang YG, Wang H, Asavaroengchai W, Dey BR. Role of Interferon-Gamma in GVHD and GVL. Cell Mol Immunol (2005) 2(5):323-9.

Conflict of Interest: Authors $\mathrm{YZ}$ and $\mathrm{AC}$ were employed by Shanghai YaKe Biotechnology Ltd..

The remaining authors declare that the research was conducted in the absence of any commercial or financial relationships that could be construed as a potential conflict of interest.

Publisher's Note: All claims expressed in this article are solely those of the authors and do not necessarily represent those of their affiliated organizations, or those of the publisher, the editors and the reviewers. Any product that may be evaluated in this article, or claim that may be made by its manufacturer, is not guaranteed or endorsed by the publisher.

Copyright (c) 2021 Ding, Wang, Hong, Zhao, Zhou, Wei, Wu, Xu, Zhang, Luo, Shi, Chang, Hu and Huang. This is an open-access article distributed under the terms of the Creative Commons Attribution License (CC BY). The use, distribution or reproduction in other forums is permitted, provided the original author(s) and the copyright owner(s) are credited and that the original publication in this journal is cited, in accordance with accepted academic practice. No use, distribution or reproduction is permitted which does not comply with these terms. 